\title{
A study on the effectiveness of online teaching in pharmacy education from teacher and student perspectives during the COVID-19 pandemic
}

\author{
Dibya Sundar Panda1 (iD), Mohammed Gamal ${ }^{1}$, Ameeduzzafar Zafar ${ }^{1}$, Della Grace Thomas Parambi ${ }^{1}$, \\ Aswini Kumar Senapati², Soraja Kumar Patro², Pratap Kumar Sahoo 3 , Anindya Bose 3 \\ ${ }^{1}$ Pharmaceutics Department, College of Pharmacy, Jouf University, Kingdom of Saudi Arabia \\ 2Institute of Pharmacy and Technology, Odisha, India \\ ${ }^{3}$ School of Pharmacy, SOA University, Bhubaneswar,Odisha, India
}

Keywords

Blackboard

Zoom

Blended Teaching

\section{Correspondence}

Dibya Sundar Panda

College of Pharmacy

Jouf University

Skaka

Kingdom of Saudi Arabia

dibyapanda1974@gmail.com

\begin{abstract}
Introduction: Technology is a proven teaching aid, and online teaching has facilitated teaching across borders; however although technology has been proved to be an effective teaching aid, it cannot replace a teacher. There are many reports that discuss the constraints of only using online classes, as a result the use of both online and face to face classes has been advocated. The COVID-19 pandemic, however, has forced teachers and lecturers to rely solely on online classes. Methods: The authors conducted a survey among the teachers and students of selected schools in India and in the Kingdom of Saudi Arabia to assess their experiences of the effectiveness of online teaching over traditional classroom teaching; the possible ways to improve the teaching and learning experiences; and to find innovative ways and means that can make online teaching more effective. The responses were then represented as percentages, and statistical analysis was conducted to find the degree of agreement. Conclusion: Some degree of agreement regarding focus in lectures, interactions and summative online assessments was found between students and faculties. Internet speed and technical issues were revealed to be the main constraints of this format, whereas flexibility, availability of content for revision, and fewer distractions were the positive features. The majority of the students and faculty felt that online teaching could not replace traditional face-to-face teaching. The use of animated and video content would help students' understanding and retention of topics. Frequent summative and formative assessments are vital to draw attention, help with retention and address the issues relating to learning and teaching.
\end{abstract}

\section{Introduction}

Today technology has become an indispensable part of everyone's lives (Mohammad et al., 2014). People use technology in almost every facet of day to day life to make their work easier and to save time. Integration of technology in teaching has made learning easier and more accessible (Knee, 1995). Online teaching has facilitated distance teaching (Jacqueline \& Smita, 2001). Although technology has been proved effective as a teaching aid, it cannot replace a teacher (Priya, 2015). Despite the widespread use of technology, we still heavily rely on traditional classroom teaching (Dimitrios et al., 2013).

Studies have been conducted around the obstacles faced by teachers using the Blackboard learning application for online teaching in universities in Saudi Arabia (Hanan \& Hassan, 2014). Whilst online teaching has been conducted successfully for humanity courses (Ibrahim, 2018), 
education related to health sciences poses many challenges. These challenges can include time constraints, poor technical skills of teaching staff, inadequate infrastructure, absence of institutional strategies or support and negative attitudes (O'Doherty et al., 2018). Several reports discuss the effectiveness of using traditional and online blended teaching in pharmacy (Schindel, et al., 2013; Lean et al., 2018).

The arrival of new drugs and advances in medical expertise create many challenges for the teaching of health specialists for professional advancement. Online teaching has generally been responsive to the rising demand for continuing pharmacy education, and current courses with e-learning methods have been demonstrated to be adaptable, user focused and easy to update (Ruggeri et al., 2013). Lorenzoni and colleagues (2019), have reviewed the literature concerning the implementation of e-learning across various specialties of pharmacy as a part of continuing education, and to see the feasibility of a distance mode of education. As DiPiro (2003) emphasises, the use of such e-learning methods should not compromise the quality of instruction or the ability of students to acquire the intended learning outcomes. Therefore, to prepare adequate e-learning requires international deliberation on pharmacy education (Anderson et al., 2012), with many internationally approved pharmacy education reports detailing realistic education and quality assurance criteria (FIP, 2017). There are reports about the successful use of online platforms in pharmacy education. One great advantage of online platforms is the advantage of unlimited access to online material without any time restrictions, allowing the students to learn at their own convenience (Leva et al., 2009; Lean et al., 2018). Tuan (2015), examined the evidence of the effectiveness of online learning, and revealed that it is comparable to traditional learning. Tuan (2015) suggested that researchers find newer and more effective online methods. The lockdown, implemented to prevent the spread of COVID-19 forced academics to conduct their classes online using a variety of platforms (Rapanta, 2020). The sessions, as well as assessments, were successfully completed online. The COVID-19 pandemic made institutions realise that there should be an alternate method for delivering lectures in these types of situation. The authors conducted a survey among the teachers and students of selected schools in India (four institutions) and in the Kingdom of Saudi Arabia (three institutions) to assess their experiences on the effectiveness of online teaching compared to traditional classroom teaching; the possible ways to improve teaching and learning experiences; and to determine innovative ways and means to make online teaching more effective.

\section{Methods}

A meeting was called among the experienced teaching faculty from various pharmacy specialties in various learning institutions to discuss the challenges faced by the students and faculty members. In an attempt to identify the challenges and difficulties, and to find out ways to cope with them, a questionnaire was prepared for both students and teachers. There was a total 12 questions, of which ten were multiple choice and two were open ended. The survey was conducted in conveniently selected schools in India (four institutions) and in the Kingdom of Saudi Arabia (three institutions). The survey link was distributed among a random list of 52 teachers and 180 students generated from a pool using MS Excel via email and Whatsapp. The survey was conducted online through Google between May and June 2020, and the responses were recorded. The opinions were scored as follows: Highly Effective $=2$, Effective $=1$, Not Effective $=$ 0 , High $=4$, Moderate $=3$, Normal $=2$ and Minimum $=1$. Statistical analysis of the data was made using student t-test (two-tail), $\mathrm{p}<0.5$ to see the degree of agreement between student and faculty experiences.

\section{Results}

A total of 148 students (64 Saudi, 82 Indian; total response rate $82 \%$ ) and 46 faculty (response rate $88 \%$ ) responded to the survey. There was no responder bias as the respondents were well distributed irrespective of their experience, specialty among faculties and level of programme for students. According to the response category, the results were categorised and given as a percentage along with a ' $p$ ' value (Table I).

The majority of faculty (39.1\%) and students (54.9\%) felt that the major constraint in taking online classes was their internet connection (Table 1). Faculty members liked the following features of online classes the most: Powerpoint and video presentations, evaluations, flexibility of time and place, social distance, no interruption from students, technically oriented and live example sharing, punctuality of students, attendance, and interactions. Whereas students liked the following features: assignments, interaction and doubt clarifications, presentation of topics, the ability to attend the classes from anywhere, receiving information without pressure, receiving attendance, explanation, no disturbances, free pass, commitment of faculty members to make it as seamless as possible, comfort of home, group discussions, the ability to record and return to lectures, one to one interaction. Faculties and students recommended the addition of the following features to the online classes: 
Table I: Response to question number 1, 2, 3, 4, 5, 6, 7, 8, 9, 12

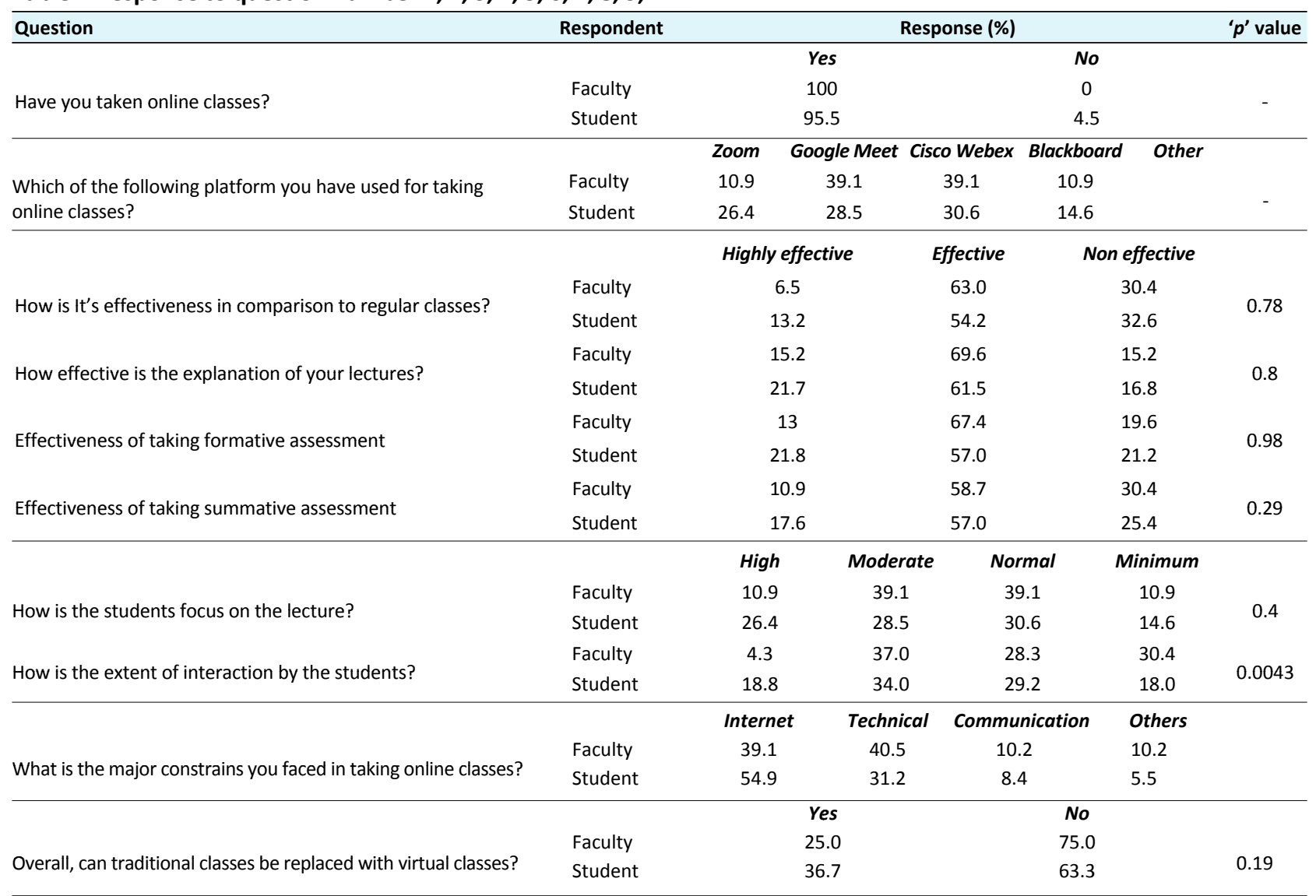

explanations given by writing on the screen, student's attention, video of the participants to check whether they are participating or not, analytics, advice on how to work with low bandwidth, minimising noise.

\section{Discussion}

This study was carried out to evaluate the effectiveness of online teaching during the COVID-19 pandemic by collecting both students' and teachers' experiences. The majority of faculty members and students felt that face-to-face traditional classes were more effective in comparison to the online classes, which is supported by the report of Dalia and colleagues (2018). There was, however, some degree of agreement about the focus in lectures, interactions and summative assessments mandating the use of online classes (Hassali et al., 2012; Ruehter et al., 2012).

Blended delivery of lectures has the advantage of flexibility of time and location (Hannay \& Tracy, 2006; Rae \& Kay, 2007) which aligns with students' opinions. The students can review the lectures as many times as needed online and have queries answered face-to-face or online in subsequent sessions. Preparing animated lectures will improve the focus and the learning experiences of the students (Owolabi, 2014). Online platforms for blended-learning courses have been used by qualified pharmacists continuing education degree programmes (Schindel et al., 2013). In this study, it was revealed that the majority of faculty members and students were of the opinion that traditional classes could not be completely replaced by online classes except in exceptional situations such as the COVID-19 pandemic. And that animated and video lessons could be effective tools for learning, as supported by an earlier study where videos were rated as a powerful teaching aid in learning clinical and pharmaceutical skills (Gormley et al., 2009).

In this study students favoured video sharing; which is substantiated by earlier reports about the preference of pictures and videos over text for the delivery of visually intensive information (Park et al., 2016). With online videos, students can view, pause and replay the content as often as required. Students and faculty liked the 
interaction facilitating content sharing by the students, online debate, and question and answer sessions, as reported by Lean and colleagues (2018).

Both faculty members and students agreed on the effectiveness of taking online summative and formative assessments, which is supported by the report from Anderson and colleagues (2009).

As for the response of the students and faculties, the major constraint to the online classes were issues relating to internet connectivity; slow connection speeds may discourage students, which agrees with the report by Husniyah (2018). It is hoped that improvements in internet connections or better development of apps which can work at low internet speeds will contribute to the improved effectiveness of online classes.

\section{Limitations}

This study has the limitation of being conducted on only a small population.

\section{Conclusion}

The majority of faculty and students were not in favour of exclusively online classes. The instantaneous decision by authorities to switch to online classes to prevent the spread of the COVID-19 virus, left no room for the teachers and students to have proper planning. Moreover, the transition to solely virtual learning posed technical challenges for both teachers and students. The students and teachers agreed that online teaching assured social distancing. Agreement regarding the focus on lectures, interaction and online summative assessment was seen between students and faculties. Increasing the internet speed of participants, inclusion of animated and video content, frequent summative and formative assessments will be instrumental in effective online teaching.

\section{Acknowledgements}

We extend our sincere thanks to all the participants of the survey.

\section{References}

Anderson, C., Bates, I., Brock, T., Brown, A.N., Bruno, A., \& Futter, B. (2012). Needs-based education in the context of globalization. American Journal of Pharmaceutical Education. 76(4), 56-61. https://doi.org/10.5688/ajpe76456
Anderson, H. (2009). Formative assessment: Evaluating the effectiveness of online quizzes in a core business finance course. Journal of Open, Flexible, and Distance Learning, 13(1), 26-40. https://doi.org/10.2139/ssrn.1385773

Dalia, A., Mohammed, G., Abdurahman, A., \& Arwa K. (2018). Pharmacy students' perceptions towards online learning in a Saudi Pharmacy School. Saudi Pharmaceutical Journal, 26, 617-621. https://doi.org/10.1016/i.jsps.2018.03.001

Dimitrios, B., Lambros, S., Kakkos, N., \& Athanasios, K. (2013) Traditional Teaching Methods Vs. Teaching Through The Application Of Information And Communication Technologies In The Accounting Field: Quo Vadis?. European Scientific Journal, 9(28), 73-101.

DiPiro, J.T. (2003). Is the quality of pharmacy education keeping up with pharmacy school expansion? American Journal of Pharmaceutical Education, 67(2), 48-52. https://doi.org/10. $\underline{1590 / s 2175-97902019000118100}$

Doherty, D.O., Marie, D., Justan, L., Ailish, H., Jason, L., \& Deirdre, M. (2018). Barriers and solutions to online learning in medical education - an integrative review. BMC Medical Education, 18, 130. https://doi.org/10.1186/s12909-018-1240-0

Gormley, G.J., Collins, K., Boohan, M., Bickle, I.C., \& Stevenson, M. (2009). Is there a place for e-learning in clinical skills? A survey of undergraduate medical students' experiences and attitudes. Medical Teacher, 31(1), 422. https://doi.org/10.1080/01421590 $\underline{802334317}$

Hanan, A.Z., \& Hassan, E.Z. (2014). Using blackboard in online learning at Saudi universities: Faculty member's perceptions and existing obstacles. International Interdisciplinary Journal of Education, 3(7), 230-7

Hannay, M., \& Tracy, N. (2006). Merlot Perceptions of Distance Learning: A Comparison of online and traditional learning. Journal of Online Learning and Teaching, 2(1), 1-12

Hassali, M., Zehan, S., Fahad, S., Maryam, F., \& Hisham, A. (2012). Assessment of students' perceptions towards e-learning management system (E-Ims) in a Malaysian pharmacy school: a descriptive study. Malaysian Journal of Public Health Medicine, 12(1), $14-20$

Husniyah., A. (2018). Blended Learning in EFL Classrooms with slow internet: Insights from teachers and students. The fourth international conference on English across cultures. Available at: https://www.researchgate.net/publication/330400197

Ibrahim, M. (2018). The Role of E-learning in Studying English as a Foreign Language in Saudi Arabia: Students' and Teachers' Perspectives. English Language Teaching, 11(5), 206-209. https://doi.org/10.5539/elt.v11n5p74

FIP [International Pharmaceutical Federation]. (2017). Research, development and evaluation strategies for pharmaceutical education and the workforce: A global report. Available at: https://www.fip.org/file/1385

Jacqueline, L., \& Smita, G. (2001). Education at the Crossroads: Online Teaching and Students' Perspectives on Distance Learning. Journal of Research on Technology in Education, 34(1). 51-57. https://doi.org/10.1080/15391523.2001.10782333 
Knee, R. (1995). Factors Limiting Technology Integration in Education: The Leadership Gap. In J. Willis, B. Robin \& D. Willis (Eds.), Proceedings of SITE 1995--Society for Information Technology \& Teacher Education International Conference. 556-560. Waynesville, NC USA: Association for the Advancement of Computing in Education (AACE). Available at: https://www.learntechlib.org/primary/p/46556/

Lean, Q.Y., Long, C.M., Yuet, Y. W., Chin, N., Maryam, F., Siti, N.F., \& Adzilah, M. (2018). Validation of online learning in pharmacy education: Effectiveness and student insight. Pharmacy Education, 18(1), 135-142

Leva, S., March, G.F., \& Elliot, E.E. (2009). Pharmacy students English language skill Development: are we heading in the right direction? Pharmacy, 9(1), 6-10

Lorenzoni, F.M., \& Soares, S.N.L. (2019). E-learning in Pharmacy Education: what do we know about it? Brazilian Journal of Pharmaceutical Sciences, 55(18), 181-188. https://doi.org/10. $\underline{1590 / \mathrm{s} 2175-97902019000118100}$

Mohammad, A.S., Maisaa A.O., Sana, B., Samar, A., \& Rizik, A.S (2014). How Technology Affects Our Life: The Case of Mobile Free Minutes in Jordan. Life Science Journal, 11(7), 417-420

Owolabi, T. (2014). Effectiveness of Animation and Multimedia Teaching on Students' Performance in Science Subjects. British Journal of Education Society \& Behavioural Science, 4(2), 201-210. http://doi.org/10.9734/BJESBS/2014/3340

Park, H.L., \& Shrewsbury, R.P. (2016). Student evaluation of online pharmaceutical compounding videos. American Journal of Pharmaceutical Education, 80(2), 30-35. https://doi.org/10. 5688/aipe80230

Kale. P. (2015). Can ICT replace the teacher in the classroom? International Journal of Educational Research Studies, 1(4), 311-316

Rae, C., \& Kay, L. (2007). Blending online learning with traditional approaches: changing practices. British Journal of Educational Technology, 38(2), 337-348. https://doi.org/10.1111/j.1467$\underline{8535.2006 .00630 . x}$

Rapanta, C., Botturi, L., Goodyear, P., Guardia, L., \& Koole, M. (2020). Online University Teaching During and After the Covid-19 Crisis: Refocusing Teacher Presence and Learning Activity. Postdigital Science and Education. https://doi.org/10.1007/ s42438-020-00155-y

Ruehter, V., Lindsey, C., Graham, M., \& Garavalia, L. (2012). Use of online modules to enhance knowledge and skills application during an introductory pharmacy practice experience. American Journal of Pharmaceutical Education, 76(4), 69-72. https://doi.org/10.5688/ajpe76469

Ruggeri, K., Farrington, C. \& Brayne, C. (2013). A global model for effective use and evaluation of e-learning in health. Telemedicine journal and e-Health: the official journal of the American Telemedicine Association, 19(4): 312-21. https://doi.org/10. 1089/tmj.2012.0175

Schnidel, T.J., Hughes, C.A., \& Sadowski, C.A. (2013). Blended Learning: Reflections on Teaching Experiences across the Pharmacy Education Continuum. Pharmacy, 1(2), 137-152. https://doi.org/10.3390/pharmacy1020137
Tuan, N. (2015). The Effectiveness of Online Learning: Beyond No Significant Difference and Future Horizons. MERLOT Journal of Online Learning and Teaching, 11(2), 309-319

Wong, T.H., Ip, E.J., Lopes, I., \& Rajagopalan, V. (2014). Pharmacy students' performance and perceptions in a flipped teaching pilot on cardiac arrhythmias. American Journal of Pharmaceutical Education, 78(10), 185-89. https://doi.org/10. 5688/ajpe7810185 